\title{
College Students' Sense Of Cycling Capability Deters Helmet Use: Implications For Safety Helmet Ordinances
}

Ronald E. Cossman, Ph.D., Mississippi State University, USA Ronald D. Williams, Jr., Ph.D., CHES, Mississippi State University, USA

Barry P. Hunt, Ed.D., Mississippi State University, USA

Catherine Ali Fratesi, MS, Mississippi State University, USA

Sarah Beth Slinkard, Mississippi State University, USA

Timothy F. Day, Mississippi State University, USA

\begin{abstract}
Proponents frequently cite increased injury protection as a reason for supporting bicycle helmet ordinances; yet, many cyclists oppose such policies. In this study, six focus groups of college students discussed cycling behaviors and attitudes toward using bicycle safety helmets, and perceptions of the local helmet ordinance. The usual concerns were voiced such as "inconvenience" and "helmet hair". Participants reported very high confidence in their cycling ability and their ability to avoid a crash which might require a helmet. They failed to take into account external factors or the actions of others which may increase risk for injury. They also did not understand how health insurance spreads the financial risk for traumatic events. These findings have implications for designing education campaigns to promote college student health, as well as initiatives for helmet ordinance advocacy.
\end{abstract}

Keywords: Bicycle Helmets; Helmet Ordinances; Safety Education; College Student Health

\section{INTRODUCTION}

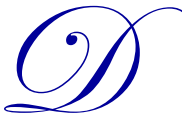

espite evidence that bicycle helmets may prevent injuries (Attewell, Glase, \& McFadden, 2001; Fullerton \& Becker, 1991; Thompson, Rivara, \& Thompson, 2000; Thompson, Thompson, Rivara, Wolf, 1990), the efficacy of helmets and compulsory helmet ordinances is still debated (Hooper \& Spicer, 2012; Robinson, 2006; Robinson, 2007; Elvik, 2011). Because it is an economical means of transportation, college students frequently cycle (Coron, 1996; Gohn \& Williams, 2009) yet, report very low rates of helmet usage (Fullerton \& Becker, 1991; Weiss, 1996). Students regularly indicate economical, physical, and social barriers to helmet use including cost, inconvenience, personal vanity, and peer ridicule (Coron \& McLaughlin, 1996; Ross, Ross, Rahman, \& Catalso, 2010; Page, Follett, Scanlan, Hammermeister, \& Friessen, 1996). Comprehensive literature review revealed only one study since 1997 which examined helmet use among U.S. college students. This study, which indicated that only $12 \%$ of college students wear helmets, focused on the development of an instrument to measure attitudes towards bicycle helmets (Ross, Ross, Rahman, \& Cataldo, 2010). As university communities explore helmet policies, it is important to more appropriately understand the attitudes of college students towards this behavior.

In 2010, the city of Starkville, Mississippi passed an ordinance requiring bike helmets for all ages; however, the local university (Mississippi State University) has no helmet requirement for on-campus cyclists. Thus, some students have become adept at the "ride and pull", as they cross on to campus removing their helmet (Figure $1)$.

The purpose of this project was to better inform safety helmet public education and awareness campaigns at the local level, particularly in university-centered communities. The objective of the study was to gather focus group data to determine student perceptions of cycling safety including objections and resistance to helmet use. The 
hypothesis was that regulatory context plays a major role in helmet usage, more so than concerns about inconvenience and personal vanity.

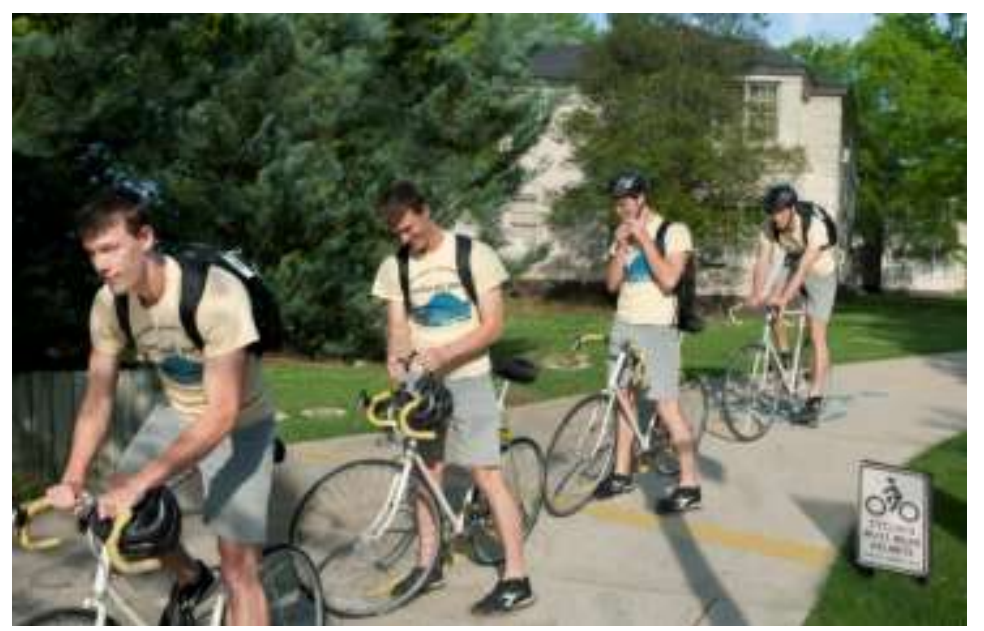

Figure 1. Photo illustration of a college student removing his bicycle helmet when entering the university campus.

\section{METHODS}

University students with experience in recreational or commuter cycling were recruited to participate in one of six different focus groups. Participants were recruited through social network postings (Facebook) and campus flyers. A total of 46 students participated (27 males, 19 females) with $93.5 \%$ of the sample consisting of undergraduate students $(n=43)$ between the ages of 15-25. Self-identified commuter cyclists made up 19.6\% ( $n=9)$ of the sample, while $80.4 \%(\mathrm{n}=37)$ self-identified as recreational cyclists. The participants were given a passive informed consent document and an opportunity to ask questions about the study prior to beginning each focus group. Each focus group was moderated by university researchers who also serve as representatives on the local city's health promotion committee. Participants were asked a set of ten questions to determine their thoughts and perceptions related to helmet ordinances, cycling safety, and personal cycling history.

\section{RESULTS}

Despite the general knowledge that safety helmets do provide protection to cyclists (Attewell, Glase, \& McFadden, 2001; Fullerton \& Becker, 1991; Thompson, Rivara, \& Thompson, 2000; Thompson, Thompson, Rivara, Wolf, 1990), few participants reported a history of helmet use as a child. Only $17.4 \%$ ( $=8$ ) participants reported being required to wear a helmet as a child $(<16$ years of age) based on parental enforcement. Behavioral continuation was evident among the sample, as the lack of childhood helmet use seemed to impact adult helmet use. Only $13.0 \%(\mathrm{n}=6)$ of participants reported consistent current use of a safety helmet when cycling for either commuter or recreational purposes. The discussion yielded several common complaints about wearing a helmet (Table 1). Of the participants who do not consistently wear helmets, it was agreed that many of them only wear a helmet in areas where they feel they are likely to get a ticket (per city ordinance) for not wearing a helmet, although only $4.3 \%(\mathrm{n}=2)$ had received a ticket.

A consistent theme among participants was to question the amount of protection that a helmet would actually provide in a crash (sample comments in Table 1). Additionally, several participants noted that helmet ordinances actually discourage cycling because students would rather not cycle than wear a safety helmet. The majority of participants $(n=43 ; 93.5 \%)$ felt that adults should not be required by law to wear a helmet, but rather should have a choice to make a decision that will only affect their own personal well-being. In contrast, 93.5\% $(n=43)$ said that children should be required to wear a helmet. Several participants voiced thoughts that the only person who assumes risk while cycling without a helmet is the cyclist. The theme of helmet use being a personal choice was consistent in all focus groups; however, participants were not able to see the impact of cycling injuries beyond the health of the cyclist. Researchers asked all participants about the financial impact of cycling injuries on 
the population and none of the 46 participants were able to explain how health insurance spreads financial risk. It should be noted that only one participant reported that he/she pays for his/her own health insurance.

No participant reported to have recently had a cycling crash and all were confident of their ability to avoid crashes. When asked about external conditions (potholes, glass in the road) or the actions of others (distracted drivers, car door opening, dog attack or squirrel running across the road), all respondents remained confident of their ability to avoid a crash. General risk perceptions related to other public safety laws varied among participants. Most were supportive of an automobile seat belt requirement because the respondent's perception is that a car is more dangerous than a bike (Table 1).

Table 1. Sample focus group comments regarding cycling behaviors and safety helmet use

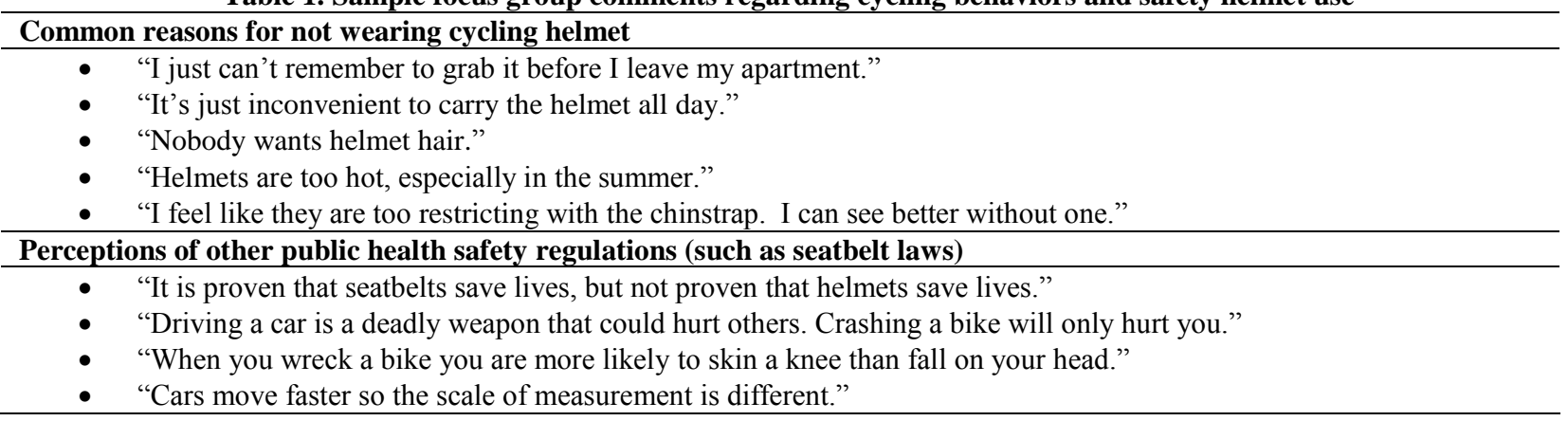

\section{CONCLUSION}

Surprisingly, some college students are not convinced that bike helmets can prevent or reduce head trauma in a crash. Rather, they envision a cycling crash as something involving a skinned knee, likely based on their childhood experiences. It was not surprising that they found wearing a helmet "restricting", "cumbersome", "overkill", and "annoying." Interestingly, only a small percentage of participants wore a helmet as a child, which seems to have impacted helmet use as an adult since most have not made cycling with a helmet a regular habit. The most striking finding was, that once young adults citied all the disadvantages to wearing a helmet, underlying their resistance was the personal belief that their own cycling ability would allow them to avoid a crash. This begs the question, should public health education campaigns take an "Everybody crashes" message to young adults? As expected, most students do not pay for their health insurance and are unaware of how health insurance spreads the financial burden of health care. This finding is important as it has potential to counter the belief that bicycle injuries only affect the individual cyclist and no one else.

\section{AUTHOR BIOGRAPHIES}

Dr. Ronald Cossman is an Associate Research Professor and Research Fellow at the Social Science Research Center at Mississippi State University. He has extensively researched the spatial analysis and visualization of health conditions using GIS and data visualization technologies to investigate the relationships between social and environmental factors. He has authored or co-authored \$1.9 million in successful grant applications related to health and safety on behalf of the local community. Ronald E. Cossman, Ph.D., Social Science Research Center, Mississippi State University, Box 5287, MSU, MS 39762 USA. Phone: 662-325-4801. E-mail: ronald.cossman@ssrc.mstate.edu

Dr. Ronald Williams, Jr. is an Assistant Professor in the Department of Food Science, Nutrition, and Health Promotion at Mississippi State University. He has extensively researched issues in social ecology of health including substance abuse prevention, primary healthcare, and health policy implications. Dr. Williams has authored or coauthored multiple community health grants and contracts totaling over \$1.6 million. Ronald D. Williams, Jr., Ph.D., CHES, (Contact Author), Department of Food Science, Nutrition, and Health Promotion, Mississippi State University, Box 9805, MSU, MS 39762 USA. Phone: 662-325-0401. E-mail: rwilliams@ fsnhp.msstate.edu (Corresponding author) 
Dr. Barry Hunt is a Professor in the Department of Food Science, Nutrition, and Health Promotion at Mississippi State University. He has extensively researched issues in community, school, and worksite health promotion. Dr. Hunt has authored or co-authored over 40 peer-reviewed publications. Barry P. Hunt, Ed.D., Department of Food Science, Nutrition, and Health Promotion, Mississippi State University, Box 9805, MSU, MS 39762 USA. Phone: 662-325-7230. E-mail: bhunt@fsnhp.msstate.edu

Catherine Ali Fratesi is a recent graduate and former Graduate Research Assistant in the Department of Food Science, Nutrition, and Health Promotion at Mississippi State University. Her primary research interest focuses on the health impact of food access. Catherine Ali Fratesi, MS, Department of Food Science, Nutrition, and Health Promotion, Mississippi State University, Box 9805, MSU, MS 39762 USA. Phone: 662-325-0626. E-mail: af77@msstate.edu

Sarah Beth Slinkard is a Graduate Research Assistant in the Department of Food Science, Nutrition, and Health Promotion at Mississippi State University. Her primary research interest focuses on health behaviors of the college student population. Sarah Beth Slinkard, Department of Food Science, Nutrition, and Health Promotion, Mississippi State University, Box 9805, MSU, MS 39762 USA. Phone: 662-325-0626. E-mail: sbs144@ msstate.edu

Timothy Day is a current health promotion graduate student in the Department of Food Science, Nutrition, and Health Promotion at Mississippi State University. His primary research interests include college health, tobacco prevention, and public health policy. Timothy F. Day, Department of Food Science, Nutrition, and Health Promotion, Mississippi State University, Box 9805, MSU, MS 39762 USA. Phone: 662-325-0401. E-mail: tfd23@msstate.edu

\section{REFERENCES}

1. Attewell, R.G., Glase, K., \& McFadden, M. (2001). Bicycle helmet efficacy: a meta-analysis. Accident Analysis and Prevention, 33, 345-352.

2. Coron, J. \& McLaughlin G. (1996). Factors influencing use of bicycle helmets among undergraduate students. Journal of American College Health, 44, 294-297.

3. Elvik, R. (2011). Publication bias and time-trend bias in meta-analysis of bicycle helmet efficacy: A reanalysis of Attewell, Glase, and McFadden, 2001. Accident Analysis and Prevention, 43, 1245-1251.

4. Fullerton, L. \& Becker, T. (1991). Moving targets: Bicycle-related injuries and helmet use among university students. Journal of American College Health, 39, 213-217.

5. Gohn, A. \& Williams, R.D. (2009, March). Analysis of bicycle consumer practices. Poster session presented at the American Alliance for Health, Physical Education, Recreation, and Dance National Convention, Tampa, FL.

6. Hooper, C. \& Spicer, J. (2012). Liberty or death; don't tread on me. Journal of Medical Ethics, 38, 338341.

7. $\quad$ Page, R.M., Follett, T.K., Scanlan, A., Hammermeister, J., \& Friessen, R. (1996). Perceived barrier, risk perception, and social norm attitudes about wearing helmets among college students. American Journal of Health Behavior, 20, 33-40.

8. Robinson, D.L. (2006). No clear evidence for countries that have enforced the wearing of helmets. British Medical Journal, 332, 722-725.

9. Robinson, D.L. (2007). Bicycle helmet legislation: Can we reach a consensus? Accident Analysis and Prevention, 39, 86-93.

10. Ross, T.P., Ross, L.T., Rahman, A., \& Cataldo, S. (2010). The bicycle helmet attitudes scale: Using the Health Belief Model to predict helmet use among undergraduates. Journal of American College Health, 59, 29-36.

11. Thompson, D.C., Rivara, F.P., \& Thompson, R.S. (2000). Helmets for preventing head and facial injuries in bicyclists. Cochrane Database of Systematic Reviews, 2, CD001855.

12. Thompson, D.C., Thompson, R.S., Rivara, F.P., \& Wolf, M.E. (1990). A case-control study of effectiveness of bicycle safety helmets in preventing facial injury. American Journal of Public Health, 80, 1471-1474.

13. Weiss, B.D. (1996). Helmet use among university bicyclists. Journal of American College Health, 44, 298301. 